The effect of rule determinacy on deciding contract disputes: Experimental data and network simulation

\author{
E. W. Wright
}

Professor and Dean of Law, Newcastle Law School, University of Newcastle, Australia

M. P. Ellinghaus

Conjoint Professor of Law, Newcastle Law School, University of Newcastle and Principal Research Fellow, Melbourne University Law School, Australia

N. M. Close

PhD Candidate, School of Psychology, University of Newcastle, Australia

Andrew Heathcote

Professor of Psychology, School of Psychology, University of Newcastle, Australia

7,275 words 


\title{
The effect of rule determinacy on deciding contract disputes: Experimental data and network simulation*
}

\begin{abstract}
This paper reports the results of an experiment in which 107 law students who had completed their first year (including a course on Contracts) were asked to decide one of 6 contract law disputes. The experiment was designed to replicate and extend earlier experiments. The disputes were based on Australian appellate cases resulting in 2:1 majority decisions. Three of them were classified as relatively 'easier' and 3 as relatively 'harder' to decide, based on the earlier experiments.
\end{abstract}

The participants were instructed to make their decisions using a statement of relevant law drawn from either Australian case law or the draft Australian Contract Code published by the Victorian Law Reform Commission in 1992. We sought to contrast two plausible points on the spectrum of 'detailed rules' to 'broad rules' that were as far apart as possible.

At 4 points in the decision process (after reading the facts, after reading the law, after formulating the arguments for each party and after their decision) the participants were asked to rate the importance of 15 facts drawn from the statement of facts. These facts had been classified by the researchers into 3 categories, based on their relative weight under both law models.

\footnotetext{
* This research was supported by the Australian Research Council (Discovery Grant DP0774419).
} 
In the extensive scholarly literature on 'rule determinacy' it is nearly universally assumed that detailed rules are more predictable than broad rules. It is also commonly asserted that a reason detailed rules are more certain is that they focus the necessary factual inquiry on a relatively small number of important facts, whereas broad rules lead decision makers to give greater importance to a relatively wider range of facts. Despite their importance, these assumptions have scarcely been tested empirically. This study contributes to that task.

Our experimental results indicate that, contrary to conventional wisdom, broad rules are as predictable as detailed rules, and are more predictable in some cases. They confirm conventional wisdom on the focussing effect of detailed rules. But this effect was not associated with greater predictability. If anything, it seemed to make some cases needlessly unpredictable.

This paper also reports our attempt to explore the assumed relationship between the scope of the factual inquiry and predictability of decisions, using a connectionist-network model to simulate the decision and fact importance rating results observed in each of the six cases used in our experiment. The model accounts for over $99 \%$ of the variance in our experimental data, using only 5 parameters for each case to account for the results of both law model groups (18 data points). Our results support the hypothesis that, again contrary to conventional wisdom, narrowing the factual inquiry reduced rather than increased predictability in all but one case. 
We explore the implications and limitations of our findings in the conclusion. Our interest in this topic arises from its relevance to the codification and international harmonization of contract law. Our results suggest that resistance to contract codes in jurisdictions like Australia and the UK, based on their indeterminacy, lacks an empirical foundation. They also suggest that a global contract code based on commonalities that can readily be discerned in existing contract codes, particularly at the level of broad rules, could be an effective instrument of contract regulation. 


\section{Introduction}

This paper reports the results of an experiment in which 107 law students were asked to decide one of 6 contract law disputes. The experiment was designed to replicate and extend earlier experiments. ${ }^{1}$ The disputes were based on Australian appellate cases resulting in 2:1 majority decisions.

The participants were instructed to make their decisions using a statement of relevant law drawn from either Australian case law or the draft Australian Contract Code (ACC). ${ }^{2}$ Australian case law, like the law of other common law countries, is a model having numerous detailed rules. The ACC purports to comprise Australian case law in just 27 Articles containing the most broadly formulated rules of contract law of which we are aware. We sought to contrast two plausible points on the spectrum of 'detailed rules' to 'broad rules' that were as far apart as possible.

At 4 points in the decision process (after reading the facts, after reading the law, after formulating the arguments for each party and after their decision) the participants were asked to rate the importance of 15 facts drawn from the statement of facts. These facts had been classified by the researchers into 3 categories, based on their relative weight under both law models.

\footnotetext{
${ }^{1}$ M P Ellinghaus and E W Wright 'The common law of contracts: are broad principles better than detailed rules? An empirical investigation' (2005) 11 Texas Wesleyan LR 399; M P Ellinghaus and E W Wright (with M Karras) Models of Contract Law: An Empirical Evaluation of Their Utility (Annandale, NSW: Themis Press, 2005).

${ }^{2}$ M P Ellinghaus and E W Wright An Australian Contract Code (Melbourne: Law Reform Commission of Victoria, 1992).
} 
We believe the contrast between detailed and broad rules of contract law will be recognized by all lawyers. The extensive body of scholarship on the 'determinacy' of legal rules, ${ }^{3}$ exploring this and similar dichotomies, ${ }^{4}$ attests to both its familiarity ${ }^{5}$ and

${ }^{3}$ This term appears to have been first used in this context by J Stone Precedent and Law (Sydney: Butterworths, 1985) pp 67-68.

${ }^{4}$ Readers familiar with the extensive body of scholarship on rule determinacy will recognize, without the need for citation, such contrasts as rules and standards, rules and principles, precise and vague, simple and complex, specific and general, hard and flexible, tailored and untailored and, even, crystal and mud. The difficulty of finding descriptive terms that can sustain analysis at the high level of abstraction characteristic of this field is eloquently described by I Ayres 'Preliminary thoughts on optimal tailoring of contractual rules' (1993) 3 So Cal Interdisciplinary LJ 1 at 2-3, 18; cf W Twining, General Jurisprudence (Cambridge: CUP, 2009) p 288. It is clear that although the language of dichotomy is used, these terms are intended merely to characterize opposing ends of a spectrum. See D Kennedy 'Form and substance in private law adjudication' (1976) 89 Harv LR 1685 at 1701; I Ehrlich and R A Posner 'An economic analysis of legal rulemaking' (1974) 3 J Leg. Studies 257 at 281; P S Atiyah and R S Summers Form And Substance in Anglo-American Law (New York: OUP, 1987) pp 71-2; M Kelman A Guide to Critical Legal Studies (Cambridge, Mass: Harvard UP, 1987) p 37; M J Radin 'Presumptive positivism and trivial cases' 14 Harv J of Law \& Public Policy 823 at 828-32; G S Geis, 'An experiment in the optimal precision of contract default rules' (2006) 80 Tulane LR 1109 at 1116; J Braithwaite, 'Rules and principles: a theory of legal certainty' (2002) 27 Aust J of Leg Phil 27 at 52 . The issue is therefore commonly formulated as one of determining the optimal determinacy of a rule: eg L Kaplow, 'Rules versus standards: an economic analysis' (1992) 42 Duke LJ 557 at 561(Kaplow, 'Rules vs standards'); see also L Kaplow, 'A model of the optimal complexity of legal rules' (1995) 152 J Law Econ \& Org 150 at 161 (Kaplow, 'Model of optimal complexity'); V Fon and F Parisi, 'The optimal specificity of legal rules' (2004) George Mason Law \& Economics Research Paper No 04-32, available at http://ssrn.com/abstract=569401 or doi:10.2139/ssrn.569401V; B Crettez, B Deffains and R Deloche, 'On the optimal complexity of law and legal rules harmonization' (2009) 142 European J Law \& Econ 127.

${ }^{5}$ Rule detail is a widely used metric in the literature on rule determinacy. The higher the level of detail, the greater the degree of determinacy: L Kaplow 'General characteristics of rules' in B Bouckaert and G De Geest (eds) Encyclopedia of Law And Economics V (Northampton, Ma: Edward Elgar, 2000) p 502 at pp 502-3 (Kaplow, 'General characteristics of rules'). See also R Pound 'Hierarchy of sources and forms in different systems of law' (1993) 7 Tulane LR 475 at 482, 485; Stone, above n 3, p 61; Ehrlich and Posner, above n 4, at 278; at pp 502, 503 502, 509 (Kaplow, 'General characteristics of rules'); Kaplow 'Rules vs standards', above n 4, at 557, 559; L Kaplow 'The value of accuracy in adjudication: an economic analysis' (1994) 23 J Leg Studies 307 at 325 (Kaplow 'The value of accuracy'); Fon and Parisi, above n 4, passim; Geis, above n 4, at 1114-16. The use of 'broad' as an antonym of 'detailed' also has antecedents: see Kaplow 'The value of accuracy' at 325; J S Kraus and R E Scott 'Contract design and the structure of contractual intent' (2009) 84 NYULR 1023 at 1059, 1062, 1072. 
significance. $^{6}$ Our interest in this topic arises from our interest in codification of contract law. ${ }^{7}$

Determinacy in the formulation of rules has always been an important issue in domestic law, but in an epoch of accelerating codification and harmonization of law it has also become a global issue. ${ }^{8}$ This is particularly true of contract law. In the great majority of the world's jurisdictions the law of contract has been codified. ${ }^{9}$ Model international codes of contract law have been published in Europe. ${ }^{10}$ The spread of contract codes to the four corners of the world inevitably puts sustained pressure on common law and other uncodified jurisdictions to fall into line. In our view, discussion of these issues must

\footnotetext{
${ }^{6}$ Determinacy of legal rules has long been of interest to legislators and scholars. In addition to the references cited in notes 4 and 5, see eg R Hillman 'Contract modification under the Restatement (Second) of Contracts' (1982) 67 Cornell LR 735 at 737; E A Farnsworth 'Some prefatory remarks: from rules to standards' (1982) 67 Cornell LR 634; R Speidel 'Restatement Second: omitted terms and contract method' (1982) 67 Cornell LR 785 at 786. The issue is also of importance to contract drafters: see J Kraus and R Scott 'Contract design and the structure of contractual intent' (2009) 84 NYULR 1023 at 1062; K Eggleston, E A. Posner and R Zeckhauser 'The design and interpretation of contracts: why complexity matters' (2000-01) 95 Northwestern LR 91; R E Scott and G G Triantis 'Anticipating litigation in contract design' (2006) 115 Yale LJ 814; A H Choi and G G Triantis 'Strategic vagueness in contract design: the case of corporate acquisitions' (2009) Univ of Virginia School of Law, John M Olin Law and Economics Research Paper Series No 2009-16, available at http://ssrn.com/abstract=1372856.

${ }^{7}$ The issue is particularly pressing for common law jurisdictions used to the high number and specificity of case law rules: see K M Sullivan 'Foreword: the justices of rules and standards' (1992) 106 Harv LR 24 at 95-96; Atiyah and Summers, above n 4, pp 75, 83; J Beatson 'Has the common law a future?' (1997) CLJ 291.

${ }^{8}$ See Fon and Parisi, above n 4; Crettez, Deffains and Deloche, above n4; Twining, above n 4, pp 301-312.

${ }^{9}$ With the enactment of the Contract Law of the People's Republic of China 1999, codified contract law governs nearly the entire world, other than common law jurisdictions: see J Gordley The Philosophical Origins of Modern Contract Doctrine (Oxford: Clarendon Press, 1991) p 1.

${ }^{10}$ See UNIDROIT Principles of International Commercial Contracts (International Institute for the Unification of Private Law, 2004); The Principles of European Contract Law (Commission on European Contract Law, 1999); C von Bar et al, Principles, Definitions and Model Rules of European Private Law: Draft Common Frame of Reference (Munich: Sellier, 2008). The Asian Development Bank has announced a project for the codification of contract law in South Pacific countries: see Asian Development Bank 'Pacific Private Sector Development Initiative Annual Progress Report' (2009), available at http://www.adb.org/Documents/Reports/Annual-Progress-Report-2009/default.asp; see also Asian Development Bank 'Reforming Pacific Contract Law' (2009), available at http://www.adb.org/PLCO/publications.asp.
} 
consider whether it is better to adopt a short code of broadly formulated rules, or a long code of many detailed rules. ${ }^{11,12}$

Moreover, the irrepressible growth of global trade and finance raises the question whether it is feasible and desirable to draft a global contract code, based on commonalities that can readily be discerned in existing contract codes, domestic and international, particularly at the level of broad rules. ${ }^{13}$

A number of costs and benefits of determinacy and indeterminacy have been identified by
scholars from a variety of perspectives, with differing conclusions on which has the

${ }^{11}$ Our dichotomy incorporates but goes beyond the conventional ambit of rules and standards, a distinction usually applied to rules that prohibit or require specified behavior - for example, driving at a particular speed (regulative rules). Contract law provides rules that define optional behaviors by which a contract is made and its content articulated, and by which it is invalidated or terminated. These constitutive rules vary as much as regulative rules in their determinacy. On the distinction between regulative and constitutive rules, see J Raz Practical Reason and Norms (London: Hutchinson, 1975) pp 108-11; F Schauer Playing by the Rules (New York: OUP, 1991) pp 6-7. According to Raz all rules are both regulative and constitutive; Schauer argues that the distinction is nevertheless meaningful: ibid, at n 13 . Compare Hart's distinction between obligation-imposing and power-conferring rules: H L A Hart, The Concept of Law (Oxford: Clarendon Press, 1970) pp 9, 27-28, 78-79, 238-40; cf H L A Hart 'Definition and theory in jurisprudence' (1983) in Essays in Jurisprudence and Philosophy (Oxford: Clarendon Press, 1983) p 21 at pp 29-30. Compare also Rawls' distinction between rules pictured as summaries of past decisions and rules pictured as defining a practice: see J Rawls 'Two concepts of rules' in M Bayles (ed) Contemporary Utilitarianism (Garden City NY: Anchor Books, 1968) p 59 at pp 80, 87-89.

${ }^{12}$ Similarly, our distinction overlaps but does not exactly correspond with the distinction between rules and principles. This is because the word 'principle' is used to refer both to rules and non-rules. Our category 'broad rules' includes principles only if they are also rules. See Pound, above, note 5 at 483; R G Dworkin 'The model of rules' (1967) 35 U Chi LR 14 at 22-29; Ehrlich and Posner, above n 4, at 259; P S Atiyah The Rise and Fall of Freedom of Contract (Oxford: Clarendon Press, 1979) pp 346-47, 352-53, 355-58; P S Atiyah, 'From principles to pragmatism: changes in the function of the judicial process and the law' (1980) 65 Iowa LR 1249 at 1250-51(Atiyah, 'From principles to pragmatism'); Stone, above, note 3, at pp 67-68, pp 238-244; Raz, above n 10, p 49; Schauer, above n 10, pp 13-14; Braithwaite, above n 4, at 50-52, 68, 73; Gordley, above n 12, pp 31-40. We have accordingly substituted 'broad rule' for the term 'broad principle' used in our previous research. On principles functioning as rules, see Atiyah and Summers, above n 4, pp 71, 95.

${ }^{13}$ Nearly all contract codes are of civilian and/or common law origin. Both civilian and common law rules of contract law are ultimately grounded in Roman law, and contain much common content: see R Zimmermann The Law of Obligations (Capetown: Juta and Kluwer, 1990) pp X-xi; cf K Zweigert and H Kötz (trans T Weir) Introduction to Comparative Law (Oxford, Clarendon, 1998) pp 24-25, 29-31. See also J Gordley Foundations of Private Law (New York: OUP, 2006) pp 3, 32, 43. Nevertheless the feasibility and desirability of a global private law have been doubted by a number of scholars who extol the benefits of pluralism: see eg R Van den Bergh 'Private law in a globalizing world: economic criteria for choosing the optimal regulatory level in a multi-level government system' in $\mathrm{M}$ Faure and A van der Walt (eds) Globalization and Private Law, The Way Forward (Cheltenham: Edward Elgar, 2010) ch 3, pp 57-96; Sieg Eiselen, 'Globalization and harmonization of international trade law', ibid ch 4, pp 97-136; see also W Twining Globalisation and Legal Theory (New York: CUP, 2006) pp 222-3, 231-2. 
greater net utility. ${ }^{14}$ In the assessment of net utility, however, one assumption is almost always adhered to explicitly or implicitly, that is that determinate rules are more predictable in their application than indeterminate rules. ${ }^{15}$ In opting for an indeterminate rule, therefore, there is always a trade-off to be made - whatever benefits its use may entail, they must exceed the disbenefit of greater unpredictability. This point is conceded even by advocates of indeterminate rules. ${ }^{16}$ It forms an important buttress of the United Kingdom's longstanding opposition to a European Contract Code or Civil Code. ${ }^{17}$ Given its pivotal importance in the discussion of the issues briefly canvassed here, and despite

\begin{abstract}
${ }^{14}$ Economic analysis: Ehrlich and Posner, above n 4; Kaplow, 'Rules vs standards', above n 4; Fon and Parisi, above $n$ 4; B Deffains and M Obidzinski 'Real options theory for law makers' (2009) 75 Recherches Economiques de Louvain 93. Behavioural analysis: R B Korobkin 'Behavioral analysis and legal form: rules vs standards revisited' (2000) 79 Oregon LR 23. Moral analysis: Pound, above n 5 at 485; Kennedy, above n 4 at 1713-1751; Kelman, above n 4, pp 5459; S Macaulay 'The real and the paper deal: empirical pictures of relationships, complexity and the urge for transparent simple rules' in D Campbell, H Collins and J Wightman (eds), Implicit Dimensions of Contract: Discrete, Relational and Network Contracts (Oxford: Hart, 2003) p 51 and (2003) 66 MLR 44.

${ }^{15}$ See eg R Pound 'The theory of judicial decision III' (1923) 36 Harv LR 940 at 951-57; Ehrlich and Posner, above n 4 at 265 (but note qualifications at 271); Atiyah, 'From principles to pragmatism', above n 11 at 1272; Atiyah and Summers, above n 4, p 73; Kelman, above n 4, pp 41-43; Kaplow, 'Rules vs standards', above n 4, pp 598, 611, 617, 621; Kaplow 'General characteristics of rules' above n 5 at p 506; Sullivan, above n 7, at 57-59; A M Gleeson 'Individualised justice - the holy grail' (1995) 69 Aust LJ 421 at 425, 430; A T von Mehren 'Some reflections on codification and case-law in the twenty-first century' (1998) 31 UC Davis LR 659 at 667; A J Hirsch 'Cognitive jurisprudence' (2002-3) 76 So Calif LR 1331 at 1342; Fon and Parisi, above n 4, at 3-4; Crettez, Deffains and Deloche, above n 4, at 134; G Dari-Mattiaci and B Deffains 'Uncertainty of law and the legal process' (2007) 163 J Institutional and Theoretical Economics 627 at 629; Deffains and Obidzinski, above n 14, pp 94, 98; J B Nash 'Instrument choice in federal court jurisdiction: rules, standards, and discretion’ (2010) Emory Public Law Research Paper No. 10-92, Emory Law and Economics Research Paper No. 10-59, available at http://ssrn.com/abstract=1553584, pp 4, 8.
\end{abstract}

${ }^{16}$ See eg Kennedy, above n 4, pp 1688-89, 1695, 1698, 1710-11; Macaulay, above n 14, pp 61-62.

${ }^{17}$ See House of Lords European Union Committee, European Contract Law: the Draft Common Frame of Reference, Report with Evidence (HL Paper 95, 2009) paras 33, 36 (non-excludable general good faith requirement reduces predictability particularly important in commercial relationships); cf S Whittaker The Draft Common Frame of Reference, An Assessment (Commissioned by Ministry of Justice, UK, 2008), available at <http://www.justice.gov.uk/publications/docs/Draft Common Frame of Reference an assessment.pdf >, pp 58, 59, 156-157 (vagueness of good faith sacrifices too much legal certainty and delegates too much discretion to the courts); D Willink 'Das englische Vertragsrecht funktioniert auch ohne Kodex' in M Eiselsberg (Hrsg), Europäisches Vertragsrecht (Vienna: Manzsche Verlags- und Universitätsbuchhandlung, 2003) p 67 (superior certainty of UK common law explains its frequent selection as law governing international contracts); Lord Hoffman 'The influence of European law on the common law in English courts', Fifth John Lehane Memorial Lecture (Sydney: 18 August 2010) para 12 ('It is easier to find the answer to any given question in English commercial law than any other.' European contract code would cause uncertainty damaging to commerce.) 
its obviously strong intuitive appeal, ${ }^{18}$ we think the assumption cries out to be tested empirically. Yet this has scarcely been done. ${ }^{19}$ Our research contributes to that task.

Among the reasons usually asserted for the superior predictability of detailed rules, is that they focus the necessary factual inquiry required in adjudication. ${ }^{20}$ This is also said to be forensically efficient, in that it also reduces the evidence required to establish a case, with obvious benefits to litigants and the courts. ${ }^{21}$ In our experiment, participants were given factual statements drawn from the reports of real cases decided using detailed rules. We could not test the effect of law model on the range of the underlying factual inquiry but we could test the assumption that detailed rules lead decision makers to focus on a narrower range of facts forming part of a fixed narrative.

In summary, the aim of our experiment was to answer two questions, at least in respect of our sample of disputes:

1. Are detailed rules more predictable than broad rules?

2. Do the law models affect the relative importance attached by decision makers to the range of facts in a case?

\footnotetext{
${ }^{18}$ It is not universally accepted: see eg Braithwaite, above $\mathrm{n} 4$, at 52-3, 59, 74-75 (broad rules are more predictable at least in 'complex actions in changing environments where large economic interests are at stake').

${ }^{19}$ Cf Geiss, above n 4. Although described as an 'experiment', Geiss' study used an economic model which compared the impact on transaction costs of a 'simple' and 'complex' default rule affecting the recovery of consequential losses in contracts in a range of assumed market conditions. He thus compared one detailed rule with one broad rule, and his work is not 'empirical' in the conventional sense. It did, however, support the conclusion that broad rules may have greater utility than detailed rules in some conditions. See also Ellinghaus and Wright, above n 1, and Ellinghaus and Wright (with Karras), above n 1.

${ }^{20}$ and other decisional tasks which involve predicting how the law would be applied to an actual or hypothetical fact situation.

${ }^{21}$ Ehrlich and Posner, above n 4, at 265-266; Kaplow, 'Rules vs standards' above n 4, at 557, 589-596; Atiyah, 'From principles to pragmatism', above n 11 at 1258; Gleeson, above n 15, at 426-427, 430-431.
} 
Contrary to conventional wisdom, our results are that broad rules were as predictable as detailed rules, and were more predictable in some cases.

Our results confirmed conventional wisdom on the focussing effect of detailed rules. However, they also raise an embarrassing question - why doesn't this effect result in greater predictability?

This paper also reports our attempt to explore the assumed relationship between the scope of factual inquiry and predictability, using a connectionist-network model based on the work of Thagard ${ }^{22}$ and Simon. ${ }^{23}$ In this model, an equal number of inferences supporting one of two possible decisions are connected to supporting facts with independently varying probabilities that a 'plaintiff' or 'defendant' supporting inference will be connected to a fact drawn from one of three categories. The effect of law model is to excite some of these connections and to inhibit others. In the 'detailed rule' condition, the probability that a connection will be inhibitory is higher, and in the 'broad rule' condition it is lower, thus mimicking the focussing effects observed in our experiment.

We used our model to simulate the decision and fact importance rating results observed in each of the six cases used in our experiment. Our results support the hypothesis that,

\footnotetext{
${ }^{22}$ K J Holyoak and P Thagard 'Analogical mapping by constraint satisfaction' (1989) 13 Cognitive Science 295; P Thagard and K Verbeurgt 'Coherence as constraint satisfaction' (1998) 22 Cognitive Science 1; P Thagard 'Causal inference in legal decision making: explanatory coherence vs Bayesian networks' (2004) 18 Applied Artificial Intelligence 231; P Thagard 'Evaluating explanations in science, law and everyday life' (2006) 15 Current Directions in Psychological Science 141.

${ }^{23}$ Principally D Simon ‘A psychological model of judicial decision making' (1998) 30 Rutgers LJ 1.
} 
again contrary to conventional wisdom, narrowing the factual inquiry reduced rather than increased predictability in all but one case.

We explore the implications and limitations of our findings in the conclusion.

\section{The experiment}

We asked 107 law students who expected to graduate within 2 years ${ }^{24}$ from an LLB or JD program at one of 9 Australian universities to decide a contract dispute, ${ }^{25}$ using statements of relevant law based on Australian case law or the draft Australian Contract Code (ACC) ${ }^{26}$ As noted in the introduction, we sought to contrast two plausible points on the spectrum of 'detailed' to 'broad' rules that were as far apart as possible. We give examples of the law statements used and elaborate their positions on the detailed - broad spectrum below.

The experiment was designed to replicate the process of adjudication as closely as practicable. We used six different disputes. ${ }^{27}$ These were chosen according to a number of criteria. First, each was based on a reported Australian appellate court case decided by a 2-1 majority. We expected that a law model effect on predictability was most likely to

\footnotetext{
${ }^{24}$ That is, these participants had completed at least the equivalent of one full academic year of study in law, including a course in contract law. The participants in our previous experiment (Ellinghaus and Wright (with M Karras), above $n$ 1) were were enrolled in a first LLB or JD course on Contracts. It could be suggested that their skills were not yet sufficiently developed to show the application of detailed rules to advantage. The more advanced participants in this study might be expected to apply detailed rules more accurately and consistently, thus showing the utility of detailed rules to better effect.

${ }^{25}$ Participants were reimbursed for their time with an Aus\$40 Amazon.com gift voucher. It took approximately 1.5 hours to complete the experiment.

${ }^{26}$ Ellinghaus and Wright, above $\mathrm{n} 2$.

${ }^{27}$ Selected from 10 disputes originally used by Ellinghaus and Wright (with M Karras), above n 1.
} 
be observed if the decisions were difficult, ${ }^{28}$ and disagreement between senior judges is an obvious indication of difficulty. Second, they covered a range of typical contract issues (formation, construction, excuses from performance, remedies). Third, to avoid possible effects of familiarity, we chose only cases that were not referred to in any detail in the standard student texts and casebooks. Finally, although these were all difficult cases in the sense just explained, 3 had been classified in our previous research as relatively 'easier' and 3 as relatively 'harder' to decide. ${ }^{29}$

The experiment was presented on the Internet and accessed by participants at a time of their choosing. On entering the site they were randomly allocated to one of 12 experimental groups (2 law models X 2 levels of difficulty X 3 cases). They were asked to read and consider a statement of facts. ${ }^{30}$ They were then (Time 1) asked to rate the importance of 15 facts taken from the narrative, using a 'Likert' scale. ${ }^{31}$

These facts had been allocated by the researchers to 3 categories according to their relative weight under the two law models. 'DB' facts were those, in our view, of greatest weight under both Case Law (detailed rules) and the ACC (broad rules). 'B' facts had relatively lower weight under both law models, although we believed they had greater

\footnotetext{
${ }^{28}$ Indeed, the results of our previous experiment indicated that the predictability of detailed rules is at its best relative to broad rules in harder cases (Ellinghaus and Wright (with Karras), ibid). Thus our selection of cases from this population minimises potential case selection bias in favour of broad rules.

${ }^{29}$ The original classification was done by ranking the 10 disputes based on the researchers' view of how clearly justice favoured one party over the other, and then dividing them into two equal groups. The easier - harder classification of the six cases used in the present study was borne out by the overall level of consensus among decision-makers in the earlier experiments, aggregated over 3 law model groups - Australian Case Law, ACC and the Unidroit Principles of International Commercial Contracts.

${ }^{30}$ These ranged between 461 - 1,145 words; the mean length was 714 words.

${ }^{31}$ The Likert scale is a standard social science research technique for obtaining quantitative measures of subjective judgments and will be familiar to many lawyers. Participants are asked to ascribe a numerical value to an attribute (often their agreement with a proposition, but in this case the 'importance of a fact to a just decision of the dispute'), using an integer scale, usually of 3,5 or 7 points (in this case, from 1 'not important' to 7 'extremely important').
} 
weight under the ACC than Case Law. 'C' (context) facts had the lowest relative weight under both models. ${ }^{32}$

Next, participants were asked to read and consider a statement of the $\operatorname{law}^{33}$ they were to use to decide their case. ${ }^{34}$ They were then asked to rank the importance of the 15 facts again (Time 2).

Next, they were asked to prepare arguments for the parties based on their law statement. ${ }^{35}$ They then rated the 15 facts again (Time 3 ).

Finally, participants were asked to assume the role of a judge and give a reasoned decision of their case, based on the statement of law they were asked to apply. They were then asked to rate the 15 facts for the final time (Time 4).

\section{Example of materials}

\section{Statement of Facts}

The statement of facts in one of the six cases, Paul v Dirk, is as follows.

\footnotetext{
${ }^{32}$ There were 5 facts in each category, and they were presented for ranking 3 at a time, including 1 of each type. The order of presentation of the facts was randomised.

33 The Case Law statements ranged between 163 - 776 words; the mean length was 463 words. The ACC statements ranged between 206 - 367 words; the mean length was 246 words.

${ }^{34}$ During this time participants could switch back and forth freely between the statement of facts and the statement of law.

35 The order in which arguments were requested (plaintiff, then defendant, and defendant, then plaintiff) was counterbalanced.
} 
Dirk is the inventor of a golfing accessory called the Stedystack. It is a device fitted to the top of golf bags to hold and sort out the clubs.

Dirk made an agreement with Paul for the joint exploitation of the Stedystack. They engaged a toolmaker, GIT, to make a die ('the Australian tool') for its manufacture. Production from this die started four years ago.

Three years ago Dirk and Paul agreed that Stedystacks should be manufactured and marketed in the United States. Paul went to the United States to put this plan into effect.

To finance the project Paul obtained a loan of $\$ 250,000$ from the Business Bank. He mortgaged his home to the Bank as security for the loan. He engaged GIT to produce a new and much better die for the American market ('the American tool') which produced a more marketable product. Stedystacks made from this die were marketed in the United States starting two years ago.

Late last year a dispute developed between Dirk and Paul. Paul wished to exclude Dirk from the United States operation, and Dirk wished to exclude Paul from the Australian operation. After lengthy negotiations Dirk and Paul signed a written contract dated 26 January of this year to settle their dispute.

The contract provided that Paul should have the exclusive right to manufacture and market the Stedystack in North and South America, and that Dirk should have the exclusive right to do so in the rest of the world. The contract also provided:

6. Dirk will within 14 days of this agreement pay out the mortgage over the residential property of Paul held by the Business Bank.

12. Paul will pay for the upgrading of the Australian tool, and when the upgrade is complete will exchange the American tool for the Australian tool. It is estimated that upgrading the Australian tool will take 12 weeks.

Dirk approached GIT to arrange for the upgrading of the Australian tool. On 2 February Dirk wrote to Paul: 
GIT have indicated that they cannot commence alterations without a deposit from you. Please cooperate with them so that the three months schedule for transfer of these tools can be achieved.

On 6 February Paul wrote to Dirk:

In regard to the payment for the modification of the Australian tool, it was to be taken care of by you and when it was completed and test run only then was I to pay for it and exchange the tools.

On 7 February Dirk wrote to Paul:

You are totally responsible for payment of any such modifications. If you are not prepared to co-operate maybe you could forget about modifications and have the tools exchanged now.

Dirk wrote several more letters declaring that he was ready and willing to discharge the mortgage over Paul's home once Paul paid GIT for the upgrading of the Australian tool and exchanged the American tool for it.

On 1 March Paul wrote:

The agreement signed on 26 January does not envisage any undertaking by me to pay for upgrading the tool. In the circumstances I shall retain the current tool in America.

On 5 March Dirk wrote:

Please confirm that you made arrangements for the payment of GIT. I do not have to release the mortgage until this condition has been satisfied.

On 23 March Dirk served a notice on Paul:

Take notice that you are required to attend at my office on 10 April with the die used for the manufacture of Stedystacks in the United States (or arrange for it to be freighted simultaneously). In default of you complying with this Notice I will sue you for damages or seek specific performance of the agreement. 
On 30 March Paul replied demanding that Dirk pay out the mortgage on his home as required by clause 6 of the contract of 26 January.

The parties met on 10 April. The following conversation took place:

Dirk: We don't have to release the house until we have the tool.

Paul: That is not what the agreement says. The agreement is that the house is to be released irrespective of whether or not the tools have been exchanged. I need to have the mortgage discharged so I can borrow more money to continue in business. You know I have no other employment.

Dirk: I'm not prepared to do that. I will never get the American tool if I release the house. Paul: What if I make installment payments for the upgrade of the tool? I'm happy to put up my home as security for the payment of installments.

Dirk: No. Without the tool there will be no release of the house. I don't trust you.

On 16 April Paul wrote to Dirk:

You have repudiated the contract of 26 January. I hereby terminate that contract in reliance on your repudiation and I intend to seek damages.

Paul has commenced an action for breach of contract against Dirk, claiming damages for loss resulting from the termination of the contract. Dirk claims that Paul was not entitled to terminate the contract. 


\section{Fact categorization}

\section{FACTS}

1. Dirk is the inventor of Stedystack.

2. Clause 12 provided that Paul would exchange the American tool for the Australian tool when the upgrade was completed.

3. Marketing of Stedystacks in the United States began two years ago.

4. The 26 January contract was signed to settle their dispute, by giving Paul exclusive rights in America and Dirk in the rest of the world.

5. The American tool was much better and produced a more marketable product.

\section{B FACTS}

1. To finance the joint exploitation of the Stedystack Paul obtained a loan of $\$ 250,000$ from the Business Bank, secured by a mortgage of his home.

2. Paul told Dirk on 10 April: "I need to have the mortgage discharged so I can borrow more money to continue in business. You know I have no other employment."

3. Dirk said to Paul on 10 April: "I will never get the US tool if I release the house ... I don't trust you."

4. Dirk wrote to Paul on 2 February: "GIT have indicated that they cannot commence alterations without a deposit from you."

5. The contract estimated that upgrading the Australian tool would take 12 weeks. 


\section{DB FACTS}

1. Clause 6 of the contract made on 26 January provided that Dirk would pay out Paul's mortgage within 14 days.

2. Clause 12 of the contract made on 26 January provided that Paul would pay for the upgrading of the Australian tool.

3. Dirk refused on 10 April to pay the mortgage until he had the American tool.

4. Paul offered on 10 April to make instalment payments for the upgrade of the tool and to put up his home as security for those payments.

5. On 1 March Paul said the agreement did not envisage any undertaking by him to pay for upgrading the tool.

\section{The Law Statements}

\section{CASE LAW}

Participants were provided with the following statement of the relevant Case Law rules drawn from the appellate judgment on which Paul v Dirk was based:

$[1]^{36}$ Breach by a party of a condition, or essential term, of a contract entitles the other party without more to regard herself or himself as discharged from further performance of the agreement.

\footnotetext{
${ }^{36}$ The rules have been numbered here to help the explication of our classification of these as 'detailed rules'. They were not numbered in the original materials.
} 
[2] If there is conduct sufficient to demonstrate that a party has repudiated the agreement the other party may accept the repudiation and regard herself or himself as discharged from further performance of the agreement.

[3] A term is essential if it appears from the general nature of the contract considered as a whole, or from some particular term or terms, that the promise is of such importance to the promisee that he or she would not have entered into the contract unless he or she had been assured of a strict or substantial performance of the promise, and that this ought to have been apparent to the promisor.

[4] The general principle applied to time stipulations is that a contractual term specifying the time for performance of a contractual obligation is not to be construed as a condition unless either the parties have expressly so provided, or the nature of the subject matter or the circumstances indicate that time was intended to be of the essence of the contract.

[5] A party repudiates a contract if he or she evinces an intention no longer to be bound by the contract or shows that he or she intends to perform the contract only in a manner substantially inconsistent with it.

[6] There is a difference between evincing an intention to carry out a contract only if and when it suits the party to do so and evincing an intention to carry out a contract as and when it suits the party to do so. In the first case the party intends not to carry out the contract at all in the event that it does not suit him or her. In the second case the party intends to carry out the contract, but only to carry it out as and when it suits him or her. It is much easier to say of the first than of the second case that the party has evinced an intention no longer to be bound by the contract or to fulfil it only in a manner substantially inconsistent with his or her obligations and not in any other way. But the outcome in the second case will depend upon the particular circumstances, including the terms of the contract.

[7] Repudiation may be inferred from continued adherence to an untenable interpretation of the contract. However, such an inference will not be made if the party asserting the wrong interpretation believes it to be correct but is willing to accept an authoritative exposition of the correct interpretation. 
[8] Breach by the promisee may or may not be an impediment to termination.

[9] As a general rule, a party in breach of a non-essential term is not prevented from rescinding for a fundamental breach or repudiation by the other party.

[10] The defaulting party may not terminate if he or she has repudiated the contract.

[11] If breach is to take away the defaulting party's right to terminate, there must be a direct causal relationship between the breach and the other party's failure to perform. The onus of proving the causal relationship lies on the other party.

[12] A party seeking to terminate a contract must show that he or she was ready and willing to perform the contract if it had not been repudiated

[13] Readiness and willingness to perform imports capacity to do so.

[14] Nothing but a substantial incapacity or definitive resolve or decision against doing in the future what the contract requires is counted as an absence of readiness and willingness.

[15] In relation to termination for actual breach, the party seeking to terminate is required to show that he or she was willing to perform except to the extent the defendant dispensed with his or her performance.

[16] In the case of an anticipatory repudiation accepted by the party seeking to terminate, the requirement of readiness and willingness extends only up to the time of acceptance. The party seeking to terminate will generally be able to show that he or she would have been able to perform at the time of performance by demonstrating at the time of acceptance that he or she was not incapacitated from such performance. 


\section{$\mathrm{ACC}$}

The Australian Contract Code has five Articles relevant to this dispute:

Article 11

A party who fails to perform, or is unwilling or unable to perform, an obligation breaches the contract, unless performance is excused.

Article 12

A party is excused from performance of a contract to the extent that it would be unconscionable for the other to insist on it.

Article 13

It may be unconscionable for a party to insist on performance if-

- that party has breached the contract

- $\quad$ performance was conditional on something happening or not happening.

Article 27

A person may not assert a right or deny an obligation to the extent that it would be unconscionable to do so.

Commentary to Article 27:

Article 27 overrides every other article in the Code. It operates whenever the application of any other article would result in the unconscionable assertion of a right or denial of an obligation.

Unconscionable is used in the Code as meaning 'offending against conscience'. 
Whether something is unconscionable must necessarily be judged by reference to both the values of the wider community and to the accepted morality of the particular environment in which it occurs. This encompasses the moralities of commercial expectations and risk allocation. The particular facts of each case, including pre- and post-contractual events, must be taken into account.

\section{The two models - detailed and broad}

It will be seen that the two law models agree broadly in their approach to the claims in Paul v Dirk. Both Case Law and ACC recognise that one party's failure or lack of readiness to perform a contract can entitle the other party to refuse performance. Both law models provide rules that determine when this will be the case. However, these rules differ significantly in number and quality.

Case Law provides 16 rules that apply to these facts. The collection contains 3 broad rules (1,2 and 8) and 13 mediating rules. Rules $3-4$ mediate the application of rule 1, rules 57 mediate rule 2 , and rules 9-16 mediate rule 8 .

By contrast, the ACC provides 4 rules. There are two overlapping broad rules (Articles 12 and 27) which are mediated by two further broad rules (Articles 11 and 13) and a Commentary. The ACC provides no detailed mediating rules. These rules lie at the extreme broad end of the broad rules-detailed rules continuum. ${ }^{37}$

\footnotetext{
${ }^{37}$ Indeed, it has been said that the ACC would 'potentially make unconscionability the focus of every dispute': J W Carter and Andrew Stewart, 'Commerce and conscience: the High Court's developing view of contract' (1993) 23 UWALR 49 at 67.
} 


\section{Results}

\section{Predictability}

The effect of rules on predictability can be measured by the level of consensus among decision-makers. If a high proportion of decision makers agree on a given result, the rules used by them can be said to be highly predictable; if as many decision makers disagree with a result as agree with it (i.e. consensus is only $50 \%$ ), the rules used by them can be said to be highly unpredictable. Table 1 shows the percentage of users of Case Law and the ACC who agreed with the majority result in easier and harder cases. ${ }^{38}$

These results show that broad rules are more, not less predictable, at least in the easier cases. This replicates our previous findings, using more fully trained participants. Although the main effects of law model and case difficulty were both statistically significant it is clear that these effects were mediated by their highly significant interaction apparent from the high level of consensus of users of the ACC deciding easier cases (see Table 1). ${ }^{39}$ It is particularly striking that the consensus of users of detailed rules was only slightly greater in easier cases than in harder cases; in contrast, the level of consensus of users of broad rules in easier cases is very close to unanimity.

\footnotetext{
${ }^{38}$ In two cases - one easier and one harder - broad and detailed rule users disagreed on the result. The data shown in Table 1 reflects the majority position under each law model. As our concern in this study is predictability and not the result as such, we are justified in passing over disagreements between users of different law models on the result (they are revisited briefly in the discussion of our model, below). Most lawyers would agree that many appellate cases that are decided by a 2:1 majority could plausibly have been decided the other way. For the record, Case Law users and ACC users failed to reach a majority consensus in one case and both rule groups disagreed with the court majority in the original case in 3 other cases.

${ }^{39}$ A Generalised Linear Model analysis of the binary consensus data was performed assuming a binomial probit link function: cf P McCullagh and J A Nelder, Generalized Linear Models (London, New York: Chapman \& Hall, 2nd edn, 1989). It revealed significant main effects of case difficulty $(\mathrm{Z}=2.01, p=.044)$ and law model $(\mathrm{Z}=2.18, p=.03)$. Simple effects analysis showed that consensus among ACC users was significantly higher than consensus among Case Law users in easier cases $(\mathrm{Z}=2.18, p=.03)$, but showed no reliable effect of law model for hard cases $(\mathrm{Z}=0.56, p=0.57)$.
} 
Table 1: Percentage consensus with majority for participants using either detailed rules or broad rules to judge each dispute averaged over cases classified as easier or harder to decide.

\begin{tabular}{ccc}
\hline & $\begin{array}{c}\text { Detailed } \\
\text { Rules }\end{array}$ & Broad Rules \\
\hline Easier & $62 \%$ & $90 \%$ \\
Harder & $59 \%$ & $66 \%$ \\
\hline
\end{tabular}

Fact importance

Figure 1 shows importance ratings, averaged over all cases, for each fact type, at each of four stages in the decision making process, for each law model group. ${ }^{40}$ (Figure 3 presents these results separately for easier and harder cases along with our model

\footnotetext{
${ }^{40}$ All analyses of fact importance used a mixed between and within participant factor analysis of variance with Greenhouse-Geisser corrections on tests involving repeated measures factors with more than 1 degree of freedom and the test probabilities provided are appropriately corrected. Figure 1 averages over difficulty as difficulty did not contribute to any reliable effects except the four-way interaction among all factors, $\mathrm{F}(6,618)=2.52, p=.02$. Simple effect analyses of each fact type showed this interaction was due to ratings of $\mathrm{C}$ facts. In particular, ratings for the two law model groups in harder and easier disputes differed as a function of time in an apparently unsystematic manner, $\mathrm{F}(3,309)=3.11, p=.027$.
} 
predictions.)

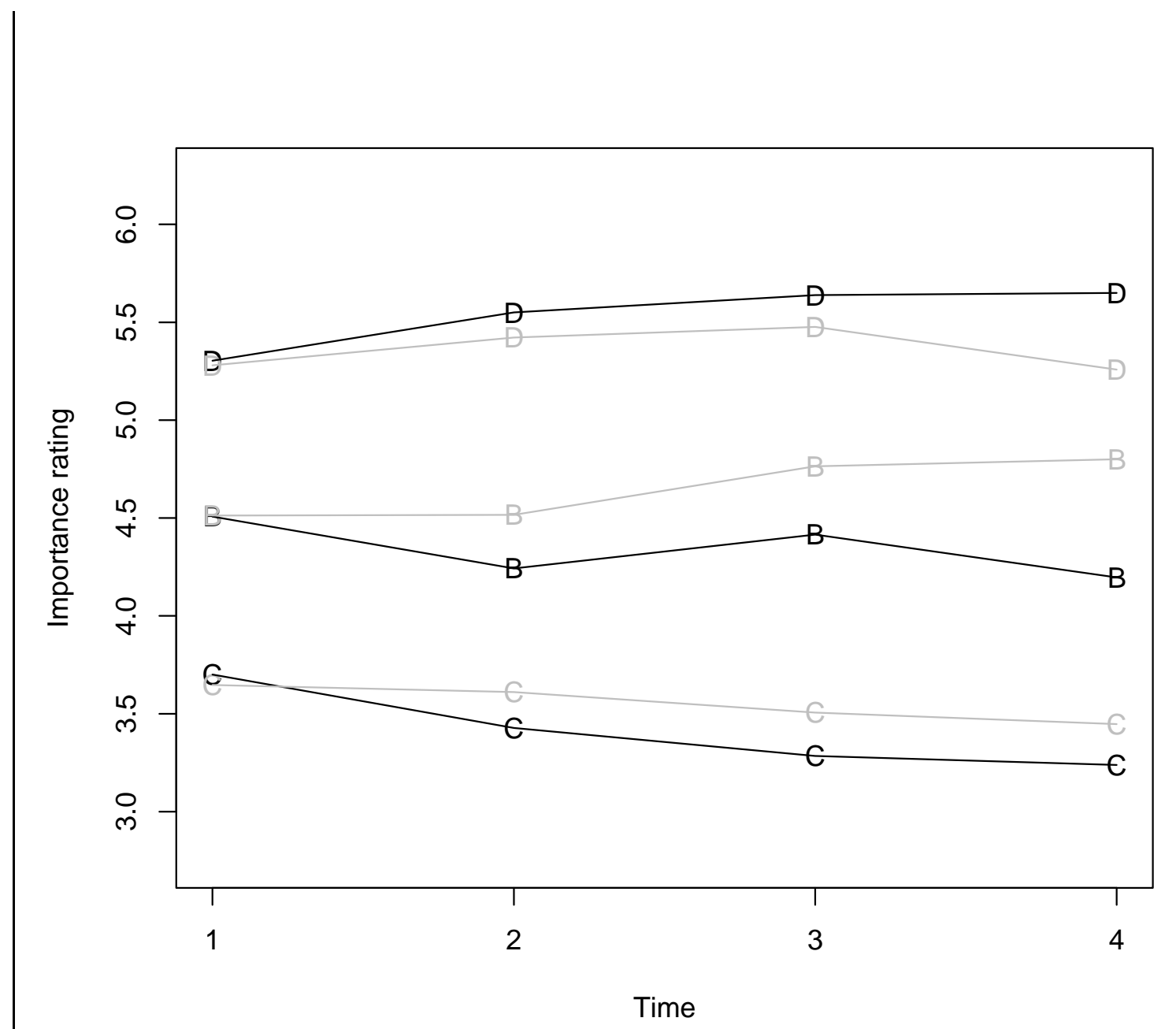

Figure 1: Overall importance rating of DB facts (symbol D), B and C facts by users of the ACC (light) and Case Law (dark) at 4 times in the decision process ( $1=$ after reading facts, $2=$ after reading law, $3=$ after constructing arguments, 4=after decision).

Several important points emerge from these data. First, the ratings at $\mathrm{T}_{1}$ (ie before the participants were given the law statement) do not differ between the two law groups. Second, the participants in the experiment shared the experimenters' view of the relative 
importance of the 3 fact categories. DB facts were ranked more important than B facts which, in turn, were ranked more important than $\mathrm{C}$ facts. ${ }^{41}$

Of greater interest is the relationship between importance ratings and law model over the course of the decision-making process. Over time the ratings of DB facts increased under both models. ${ }^{42}$ The ratings of $\mathrm{C}$ facts under both models declined over time. However, the importance ratings of B facts by ACC users rose over time, while the ratings of Case Law users declined. ${ }^{43}$

Our results thus confirm that the determinacy of rules affects the importance attached to the facts of a dispute and, in particular, that users of detailed rules attach relatively greater weight to a narrower range of facts, while broad rule users attach more weight to a wider range of facts. While this finding conforms to conventional wisdom, it is not associated with the conventionally hypothesized effect on predictability.

We think our experimental data suggest two interesting possibilities about the relationship between rule determinacy, fact evaluation and predictability.

\footnotetext{
${ }^{41}$ The main effect of fact type was highly significant, $\mathrm{F}(2,212)=167.3, \mathrm{p}<.001$.

42 The apparent decline in ratings by users of broad rules post-decision invites curiosity but is not statistically significant.

${ }^{43}$ There were highly significant interactions between fact type and time, $\mathrm{F}(6,618)=5.4, p<.001$, and between fact type, time and law model, $\mathrm{F}(6,618)=2.95, p<.01$. Simple effects analysis of each fact type showed that these interactions were due to (a) increasing ratings with time for $\mathrm{DB}$ facts, $\mathrm{F}(3,309)=3.26, p=.022$, (b) decreasing ratings with time for $\mathrm{C}$ facts, $\mathrm{F}(3,309)=4.98, p<.01$, and (c) a marginally significant interaction between the effects of time and law model for B facts due to an increase over time for ACC users and a decrease over time for Case Law users, $\mathrm{F}(3,309)=2.56, p=0.055$.
} 
The first is that the law model effects on fact weighting and consensus among decision makers are causally connected, but not in the manner conventionally assumed. What is it about the easier cases in our study that led to such a high level of consensus amongst ACC users? Why did decision makers using detailed rules seem to find them just as difficult as the harder cases? The hypothesis plainly suggested by our fact importance data is that the difference lies in the tendency of the B facts in these cases to support inferences strongly favoring one party over the other. As they increase the weight given to these facts, broad rules lead to greater consistency among decision makers. In contrast, as detailed rules diminish the weight given to these facts, they lead to greater inconsistency. Similarly, we can also reasonably hypothesize that the DB facts in these cases tend to support opposing inferences that are closely balanced between the parties this would fit with the fact that our disputes were based on appellate cases that resulted in split decisions, using case law.

Secondly, we may note that the importance ratings of the 3 groups of facts changed over the course of reaching a decision in accordance with their relative weight under the two law models. Another way of thinking about this result is to consider that participant weightings of individual facts changed so as to increase their coherence with the participant's emerging decision, that is, the pattern of our data is related to the phenomenon of 'coherence shift'. ${ }^{44}$ This suggests a possible clue about the mechanism

\footnotetext{
${ }^{44}$ In Holyoak and Simon's paradigm (K J Holyoak and D Simon, 'Bidirectional reasoning in decision making by constraint satisfaction' (1999) 128 J Experimental Psychology: General 3), participants were asked to rate their agreement with arguments that supported either the plaintiff or the defendant at several stages of deciding a dispute (including a 'pre-test' in which the arguments were presented, in a relevant context, before participants read the facts of the dispute). Ratings of agreement with arguments that were congruent with the eventual decision increased, while agreement with inconsistent arguments decreased. Our design is similar, although of course, we asked participants to
} 
underlying the effect of rule determinacy on the cognitive process of legal decision making.

The model we present below pursues these ideas further.

\section{The model}

Drawing on the work of Thagard ${ }^{45}$ and Simon ${ }^{46}$, we developed a connectionist network model of the tasks of weighing the facts and making a decision required by our experiment. The essential details of this model are as follows:

\section{The model simulates networks by using probabilistic processes to determine} connections among units within a given network. ${ }^{47}$ The simulation of each case

rate the importance of facts at several stages of deciding a dispute. The 'shifts' observed in importance ratings of the 3 fact groupings are consistent with their relevance to the decisional inferences required by the rules.

45 Thagard is the pioneer in connectionist network modeling of complex cognitive processes, including legal decision making. Among his many contributions to this field are the suggestions that legal decisions can be thought of as 'coherence problems' and that coherence can be understood as 'maximal constraint satisfaction' when all constraints cannot be satisfied: see eg Thagard and Verbeurgt, above n 22, at 2. He has argued that connectionist networks are a plausible representation of neural networks in the brain (P Thagard 'Explanatory coherence' (1989) 12(3) Behavioral and Brain Sciences 435) and has demonstrated that a connectionist algorithm is a comparatively efficient (albeit, like humans, sometimes imperfect and variable) method of computing maximal constraint satisfaction that can be used to mimic legal decision making: Thagard, ibid at 435; Thagard (2004), above $n$ 22, at 231; Thagard (2006), above $n 22$ at 141.

${ }^{46}$ Simon has been instrumental in introducing connectionist network theory to lawyers. His well-known article, 'A psychological model of judicial decision making' (above n 23) makes a compelling argument for understanding the reflective writings of several eminent American jurists within this framework, and his experimental work has demonstrated that 'coherence shift' - an expected by-product of reasoning by maximizing constraint satisfaction in difficult cases like appeals - is an empirically observable phenomenon and the mechanism - not consequence - of decision making. See Holyoak and Simon, above n 44; D Simon, L B Pham, Q A Le and K J Holyoak 'The emergence of coherence over the course of decision making' (2001) 24 J Experimental Psychology: Learning, Memory \& Cognition 1250; D Simon, D C Krawczyk and K J Holyoak 'Construction of preferences by constraint satisfaction' (2004) 15(5) Psychological Science 331; D Simon 'A third view of the cognitive coherence in legal decision making' (2004) 71 U Chi LR 511, at 511; D Simon, C J Snow and S J Read 'The redux of cognitive consistency theories: evidence judgments by constraint satisfaction' (2004) 86 J Personality \& Social Psychology 814. 
used a large set of 1000 networks. Each network in this set of 1000 can be thought of as the cognitive representation of a particular case, in the mind of a randomly assigned decision-maker.

2. Each network includes 15 'fact units'. ${ }^{48}$ As well there are 30 'story units' representing legally significant inferences that can be drawn from the facts, divided into two pools, one pool favoring the plaintiff and one favoring the defendant. ${ }^{49}$ Story units can be connected with other story units in the same pool by excitatory connections, and story units in opposing pools by inhibitory connections. $^{50}$

3. Our 3 experimental fact categories (C, B and DB) are represented by independent probabilities of connection between 3 groups of 5 facts to plaintiff and defendant story units ie., $p_{\mathrm{p}}=\left(p_{\mathrm{Cp}}, p_{\mathrm{Bp}}, p_{\mathrm{DBp}}\right)$ and $p_{\mathrm{d}}=\left(p_{\mathrm{Cd}}, p_{\mathrm{Bd}}, p_{\mathrm{DBd}}\right) .{ }^{51}$ The method used in our simulations for estimating these values, and our study hypothesis, are described in detail below.

\footnotetext{
${ }^{47}$ Rather than hand coding connections to represent relationships specific to a particular case as, for example, was done by Thagard (2004), above $\mathrm{n} 22$, at 231 . The probabilistic approach has the virtue of producing potentially different outcomes from network to network, just as outcomes differ from person to person, although of course the results we report are averaged over networks, just as our experimental results are averaged over participants.

${ }^{48}$ Fact units have a constant activation of one, and only excitatory connections with story units (ie a fact unit - story unit connection means that the latter is supported by the former). The exact values used for activations of fact units and the strength of their connections to story units are not critical.

${ }^{49}$ The simulations reported here used 15 story units in each pool. However, larger and smaller numbers produced a similar pattern of results.

${ }^{50}$ For the purposes of our simulations, the probability of excitatory and inhibitory connections between any two story units was equal and comparatively low $(\mathrm{p}=0.1)$. The absolute level of this probability did not matter, but changes in the relative probabilities of excitatory and inhibitory connections had a large effect. The initial activation of story units was also set at a uniform and low value (0.01).

${ }^{51}$ As noted above, the simulations reported here used 15 fact units. Simulation results for larger and smaller numbers (with equal numbers in each category) were similar.
} 
4. The rules are represented by a rule unit which can have either inhibitory or excitatory connections to story units. ${ }^{52}$ The two rule conditions were simulated by differing probabilities of excitatory connections (connections were set to be inhibitory if they were not excitatory). In the detailed rule condition this probability was proportional to the number of DB fact connections, whereas in the broad rule condition the probability of an excitatory connection was proportional to the number of $\mathrm{DB}$ and $\mathrm{B}$ fact connections. ${ }^{53}$ Thus the relative tendency of detailed rule units is to have a greater inhibitory effect than broad rule units, and this effect varies according to the number of B fact connections, in line with both our experimental results and conventional wisdom. ${ }^{54}$

A pictorial representation of the model is provided in Figure 2.

\footnotetext{
${ }^{52}$ As for fact units, the rule unit activation level was set at 1 but the actual values were not critical.

53 That is, the probability of an excitatory connection for story unit $i$ was, in the detailed rule condition, $p_{\mathrm{i}}=\mathrm{DB} /(\mathrm{DB}+\mathrm{B}+\mathrm{C})$, while in the broad rule condition it was $p_{\mathrm{i}}=(\mathrm{DB}+\mathrm{B}) /(\mathrm{DB}+\mathrm{B}+\mathrm{C})$, where $\mathrm{DB}, \mathrm{B}$ and $\mathrm{C}$ are the number of connections which the story unit receives from $\mathrm{DB}, \mathrm{B}$ and $\mathrm{C}$ fact units. For example, if a story unit received only connections from DB facts it would be excited by either rule unit with equal probability. On the other hand if it received no connections from DB facts it would be inhibited by a detailed rule unit, but it might instead be excited by a broad rule unit if it had B fact connections. This feature of the model is a computationally simple way of capturing the variability among fact situations, bearing in mind that our experimental categorisation of facts could not, in the nature of things, be based on 'bright-line' boundaries.

${ }^{54}$ See above $\mathrm{n} 21$.
} 
Figure 2. Pictorial representation of network model

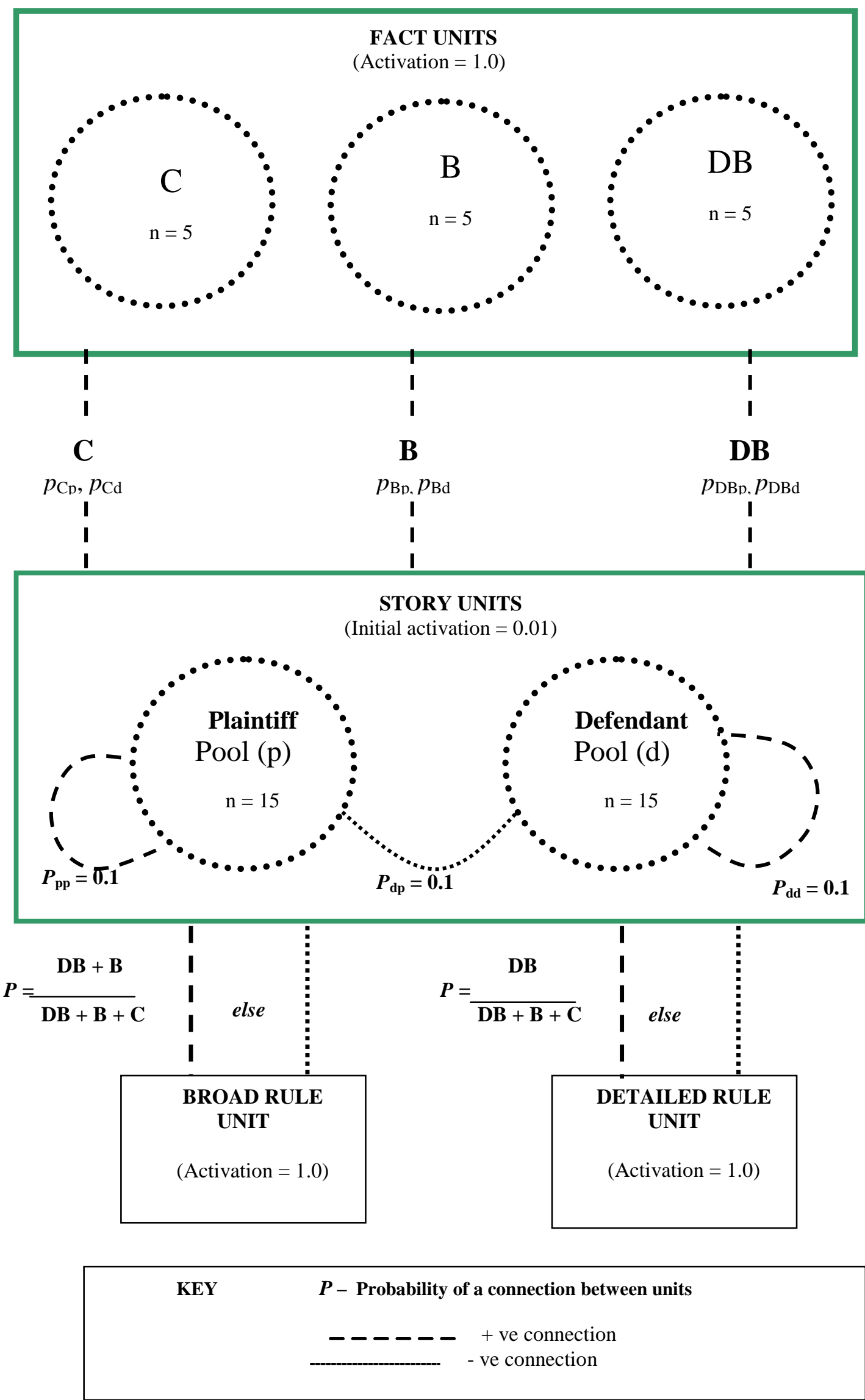


The constraint satisfaction computation process begins with an iteration that chooses one story unit at random and, using the standard algorithm, making a small adjustment of its activation level, upward or downward, whichever increases constraint satisfaction. ${ }^{55}$ The process then continues through successive iterations. At any point a decision in favor of plaintiff or defendant can be read off by determining which pool has the greatest summed activation (ie has the most excited and least inhibited units overall). 'Fact importance' values for the 3 categories of facts can also be calculated by summing the activation levels of all story units to which fact units in each category are connected. The values reported here are proportional or relative weightings, calculated by dividing the sum of activations for each category by the sum of the activation levels of story units for all category connections. (In order to compare the model's predicted values with our experimental data, we have likewise converted the latter from the 7 point Likert scale to relative values on a scale of 0 - 1.)

We used this model to simulate the experimental consensus and fact importance data for each of the six cases used in our study. Fact-inference connection probabilities involving $\mathrm{DB}$ and $\mathrm{B}$ facts $\left(p_{\mathrm{DBp}}, p_{\mathrm{Bp}}\right.$ and $\left.p_{\mathrm{DBd},} p_{\mathrm{Bd}}\right)$ were free parameters, as was a single value for the connection probability between both plaintiff and defendant story units and $\mathrm{C}$ facts (denoted $\left.p_{\mathrm{Cpd}}\right){ }^{56}$ These parameters were estimated by minimizing the sum of squared

\footnotetext{
55 The standard update equations for constraint satisfaction networks were used. Assuming unit $i$ has a total input $n e t_{i}=$ $\sum_{j} A_{j} W_{j i}$ (where $A_{j}$ is the activation of, and $W_{j i}$ the weight of the connection from, the $j^{\text {th }}$ input unit), the update on iteration $t$ when $n e t_{i} \geq 0$ was $A_{i}(t+1)=A_{i}(t) \times d+(1-d)\left(1-A_{i}(t)\right) \times n e t_{i}$, and when $n e t_{i}<0$ was $A_{i}(t+1)=A_{i}(t) \times d+$ $(1-d)\left(1+A_{i}(t)\right) \times n^{2} t_{i}$. A value of $d$ close to one (we used $d=0.99$ in our simulations) results in the gradual change in activation necessary for a smooth increase in satisfaction of the constraints.

${ }^{56} \mathrm{We}$ also conducted simulations in which $p_{\mathrm{Cp}}$ and $p_{\mathrm{Cd}}$ were allowed to vary independently. This extra flexibility was not needed to fit the data, as indicated by the tiny improvement in fit. See further text accompanying note 59, below. Although, of course, our categorization of facts was relative and not based on bright line boundaries, the notion
} 
differences between our experimental results and the values predicted by the model. ${ }^{57}$ Based on the hypotheses we advanced in the discussion of our experimental results, we expected that-

- the difference between $p_{\mathrm{DBp}}$ and $p_{\mathrm{DBd}}$ would be generally low and related to the low level of consensus among decision makers using detailed rules,

- as the difference between the consensus levels increased between the broad and detailed rule conditions, so would the difference between the values of $p_{\mathrm{Bp}}$ and $p_{\text {Bd}}$.

Each network was run through 10 updates before any input from the rule condition was introduced, and 'fact importance' values for the 3 categories of facts were then calculated, mimicking the importance ratings in our experiment after the participants had read the facts and before they had considered the law. Thereafter the simulation was extended for a further 40 updates, with fact importance readings being take at updates 15, 25 and 50, mimicking the 3 further stages of our experiment. The decision was read off at the end of 50 updates. $^{58}$ At each step of the fitting process a large enough number of networks was simulated so that the average results were sufficiently exact.

underlying our categorization of $\mathrm{C}$ facts was that that they were in some sense 'neutral'. Our simulation results tend to confirm this.

${ }^{57}$ For this purpose the predicted consensus level was weighted equally with the 12 fact importance ratings. Reasonable variations in the weighting of each type of result (that is, variations that did not allow either type to dominate completely) produced similar results.

${ }^{58}$ At the end of 50 updates fact importance was no longer changing. Although story unit activation did change further after this point, the change did not alter the decision. 


\section{Results}

Figure 3 shows the model consensus and fact importance results compared with our experimental results, for easier and harder cases. Although this information may seem, initially, confusing or overwhelming, the point of Figure 3 is merely to show visually just how good the fits are between our experimental data (the dark series in each panel) and the model predicted fact rating data (the light series in each panel). The model accounts for over $99 \%$ of the variance in our experimental data, using only 5 parameters for each case to account for the results of both law model groups. ${ }^{59}$

\footnotetext{
${ }^{59}$ Data for each case consists of, for each law model group, 9 independent data points, one consensus value and 8 relative importance ratings (as ratings are relative the remaining 4 importance ratings are not independent). Hence, the 18 data points per case are modeled by 5 estimated parameters.
} 

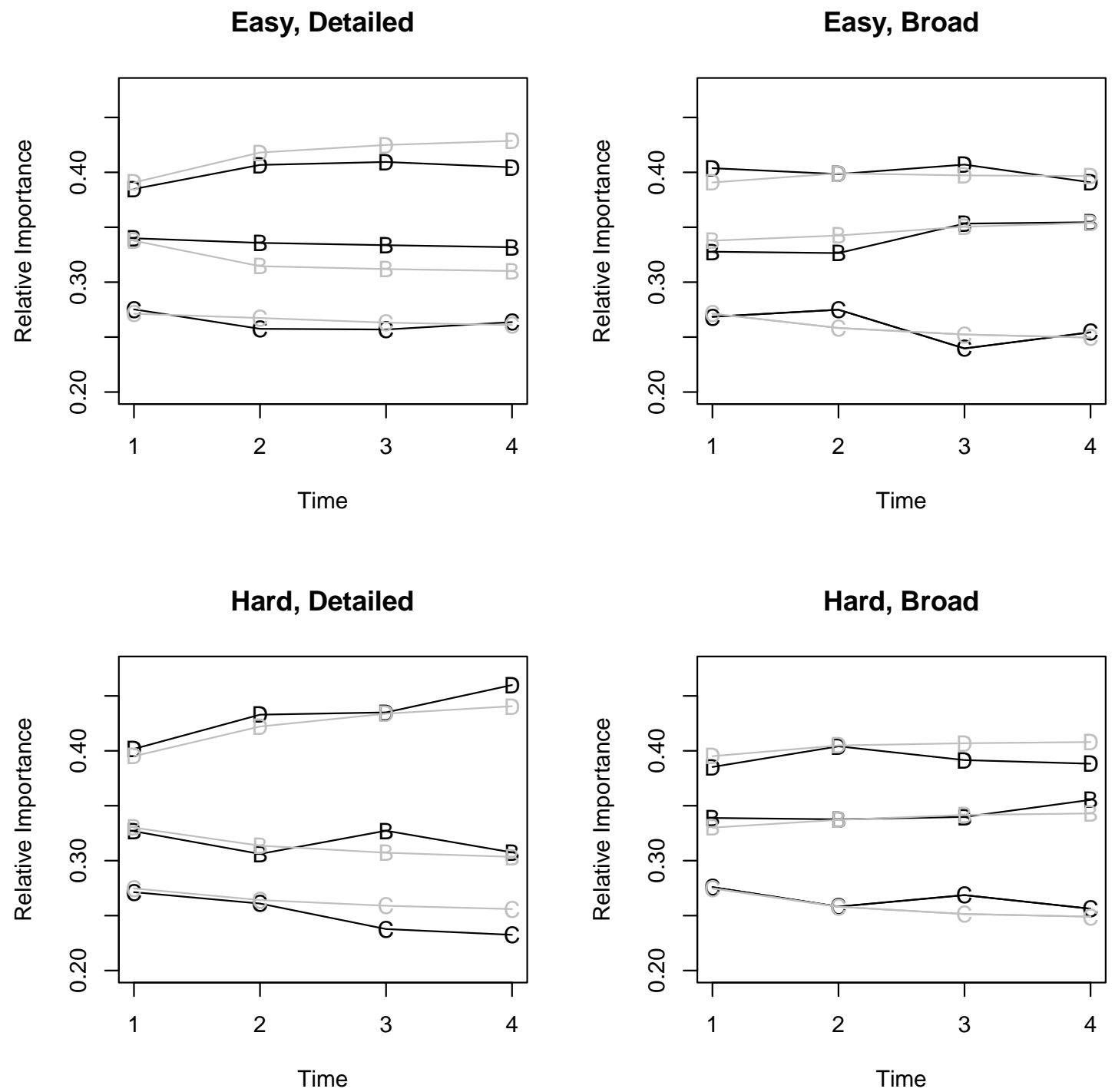

Figure 3. Relative importance ratings for data (dark) and model fits (light) for detailed and broad rule facts (symbol D), broad rule facts (symbol B) and context facts (C) at each time (1..4) for each law model group (Detailed and Broad rules) averaged over the three cases of each type (Hard and Easy). 
Table 2 shows the experimental and the predicted consensus with majority figures in each case, and the fact connection probabilities that generated these fits. ${ }^{60}$

In accordance with our hypotheses, the simulation data suggests that the phenomenon underlying the greater predictability of broad rules in some cases is the tendency of the broad rule facts in those cases to favor one party over the other more strongly. Looking across the 6 individual cases, there is a strong, obvious relationship between the differences in the probabilities of B fact connections in favor of the winning and losing party, and the difference in consensus level between decision makers using broad rules and detailed rules. In contrast, the differences between the probabilities of DB fact connections favoring the plaintiff and the defendant are comparatively small, and this is reflected in the relatively low levels of consensus in the result among detailed rule users. This is, again, in line with our hypotheses.

\footnotetext{
${ }^{60}$ These were the same simulations used to produce Figures 3. The majority decision was for the plaintiff in all cases except Case 3, detailed rule uses, and Case 4, broad rule users.
} 
Table 2: Experimental data and model predicted $\%$ consensus with majority decision, and best fit fact connection probabilities, by case.

\begin{tabular}{|c|c|c|c|c|c|c|c|}
\hline \multirow[t]{2}{*}{$\begin{array}{l}\text { Case } \\
\text { (Difficulty) }\end{array}$} & \multirow[t]{2}{*}{$\begin{array}{c}\text { Law } \\
\text { model }\end{array}$} & \multicolumn{2}{|c|}{ Consensus } & \multirow{2}{*}{$\begin{array}{l}P_{p}= \\
P_{d}=\end{array}$} & \multirow{2}{*}{$\begin{array}{l}\text { (PCp), } \\
\text { (PCd) }\end{array}$} & \multirow{2}{*}{$\begin{array}{l}\text { PBp, } \\
\text { PBd, }\end{array}$} & \multirow{2}{*}{$\begin{array}{l}\text { PDBp)/ } \\
\text { PDBd) }\end{array}$} \\
\hline & & data & predicted & & & & \\
\hline \multirow[t]{2}{*}{1 (hard) } & DR & 56 & 55 & & 0.37 & 0.38 & 0.45 \\
\hline & $B R$ & 50 & 50 & & 0.37 & 0.4 & 0.42 \\
\hline \multirow[t]{2}{*}{2 (hard) } & DR & 62 & 62 & & 0.28 & 0.47 & 0.5 \\
\hline & $B R$ & 70 & 70 & & 0.28 & 0.31 & 0.45 \\
\hline \multirow[t]{2}{*}{3 (hard) } & DR & 60 & 60 & & 0.28 & 0.51 & 0.42 \\
\hline & $B R$ & 78 & 78 & & 0.28 & 0.16 & 0.49 \\
\hline \multirow[t]{2}{*}{4 (easy) } & DR & 56 & 56 & & 0.26 & 0.28 & 0.48 \\
\hline & $\mathrm{BR}$ & 70 & 70 & & 0.26 & 0.54 & 0.42 \\
\hline \multirow[t]{2}{*}{5 (easy) } & DR & 80 & 79 & & 0.38 & 0.74 & 0.62 \\
\hline & $\mathrm{BR}$ & 100 & 100 & & 0.38 & 0.06 & 0.52 \\
\hline \multirow[t]{2}{*}{6 (easy) } & DR & 50 & 52 & & 0.45 & 0.83 & 0.48 \\
\hline & $B R$ & 100 & 100 & & 0.45 & 0.02 & 0.64 \\
\hline
\end{tabular}

\section{Discussion and conclusion}

The experiment confirmed the finding of our earlier experiments that, contrary to the conventional assumption, broad rules are at least as, if not more, predictable than detailed rules in some cases. In fact, the consensus among broad rule users was significantly higher than consensus among detailed rule users in 'easier' cases.

Our experimental results also confirmed that detailed rules led decision makers to attach relatively greater importance to a narrower range of the facts of a dispute. But this effect was not associated with greater predictability. The results raise the possibility that the 
tendency of broad rules to lead decision makers to give greater weight to a wider range of facts is, contrary to the conventional expectation, the reason for their greater predictability in some cases. Our simulation results support this hypothesis and, equally, suggest that the inhibitory tendency of detailed rules makes some disputes needlessly unpredictable.

It is commonly asserted that the tendency of broad rules to make a wider range of facts important makes adjudication less efficient and more costly. Our paradigm did not, of course, allow us to study the effect of determinacy on fact investigation - the facts given to our decision makers were all to be found in the report of the original cases on which our disputes were based. But our finding that this tendency of broad rules increases predictability in some cases is a clear offset - albeit of unknown extent - to any supposed adjudicative inefficiency. ${ }^{61}$

Our research also adds to other demonstrations of the capacity of connectionist networks to model and explain empirical data on legal decision-making. In particular, our model suggests a plausible way of thinking about and exploring the effect of rule determinacy on the cognitive process of determining legal disputes.

Our findings, of course, are subject to a number of limitations inherent in our design. The task required law students to decide a dispute. These were not judges or experienced lawyers or, for that matter, 'lay' people who might need to predict the outcome of an actual or potential dispute. They did not have the benefit of submissions from counsel,

\footnotetext{
${ }^{61}$ Indeed, our experimental results encourage us to speculate that the two original cases on which Cases 5 and 6 were based might not have resulted in appeals, or even litigation, had the ACC been the applicable law.
} 
they were asked to generate the arguments for the parties themselves. The facts were set out in a summary of only a few pages. The decision makers spent only about an hour and a half on the task. It is obviously desirable that the effects of rule determinacy should be explored using more and less (arguably) experienced decision makers in a range of contexts. Nevertheless, the task was very similar to the form of problem-based learning and assessment used in law schools to prepare students for their professional lives. The participants in this experiment were comparatively more advanced in their legal training, and thus could be expected to apply detailed rules with greater skill than the novice law students who participated in our earlier experiments.

We have contrasted only two law models. ${ }^{62}$ Although the comparison of 'detailed' and 'broad' models based is both justified and valid, we readily concede that the comparison could be more 'nuanced" ${ }^{63}$ and should be extended to other examples of broad and detailed codes. $^{64}$

Our results are also, in some ways, confined to the cases we used in this study. We do not assert that broad rules lead to more predictable decisions in all cases. Indeed, in one case in this study this was plainly not so. It can, of course, be argued that it is by no means a

\footnotetext{
${ }^{62}$ Our previous research compared a third model, the Unidroit Principles of International Commercial Contracts, which is a detailed code. The consensus results, although nominally higher in easier cases than consensus among Case Law users, were not significantly different from the Case Law results (300 decision makers in each law model group decided one of 10 cases). See Ellinghaus and Wright, above $n 1$ and Ellinghaus and Wright (with Karras), above $n 1$.

${ }^{63}$ Although we contend that Australian Case Law is rightly characterized as a 'detailed rule model', it contains some broadly formulated rules and these are more dominant in relation to some issues.

${ }^{64}$ Our broadly ranging research on codification since 1992 has led us to conclude that the ACC probably goes too far in its brevity. But we believe that a working code of contract law could be based on as few as 75 articles. We note, in this connection, that the General Part of the Contract Law of the Peoples Republic of China contains just 129 articles, many of them containing broad rules. It might usefully be contrasted with, for example, the American Restatement of the Law, Second, Contracts, consisting of 385 sections.
} 
bad thing that legal rules should draw the attention of decision makers to the real difficulties of deciding a dispute. But we will leave that argument to another day. For now we would simply emphasize that the disputes used in this study were not fictitious constructions invented by the researchers but were closely based on actual appellate cases. And while they are not, strictly speaking, a random sample of the population of appellate disputes, they were nevertheless chosen as being representative of the range of contract disputes which typically come before appellate courts. Appeals, of course, have more than a passing claim to practical significance in the real world of legal decisionmaking. But, again, it is obviously desirable that future research should explore the effects of rule determinacy in a larger number and wider range of disputes.

The conventional assumption that detailed rules are more predictable underpins opposition in common law countries, such as Australia and the U.K., to the codification of contract law. At the very least, the conventional assumption lacks an empirical foundation, and must now be considered in doubt. We believe, further, that our results indicate that the idea that a code based on broad rules could be an effective instrument of contract regulation deserves to be taken seriously. 